\title{
LA EDUCACIÓN INDÍGENA Y SUS DESAFÍOS ACTUALES
}

INDIGENOUS EDUCATION AND

THEIR CURRENT CHALLENGES

Bartomeu Melià*

La educación es una experiencia que no comienza hasta que se siente y se vive. Cada uno es protagonista de su educación, porque lo es de su palabra. Esta experiencia se hace en el tiempo, y tiene memoria. La educación de cada persona y de cada pueblo tiene pues una historia. Propondría que cada uno de nosotros hiciera historia de su propia educación: Dónde comienza la memoria de mi educación? Con quién? En qué lengua? Con qué fin?

\section{EDUCACIÓN INDÍGENA}

Pero existe también una historia de la educación indígena que va más allá de mi propia educación individual. Ahí entra la concepción de persona bastante diferente de la que se maneja en la filosofía occidental. Los pueblos indígenas que ahora están en América ya tuvieron tantas formas de educación como numerosos son ellos. Por comparación de rasgos semejantes pueden agruparse en círculos o haces -feixes- culturales. La mayoría de ellos, si no todos, se educan para alcanzar del ideal de persona que les define, y que suele estar dado en su autodenominación: se quiere ser un buen avá, ser un buen mbyá, ser un buen mykỹ, ser un buen rikbaktasa, ser un buen xokleng, un buen awé, pueblo auténtico (dice el que llamamos xavante); un buen boé, gente buena, se define el Bororo.

La educación indígena no es solamente un objeto exótico, testigo admirable de otras formas de vivir, pero ya pasadas y obsoletas.

\footnotetext{
* Doctor en Ciencias Religiosas; Integra la Comisión Nacional de Bilingüismo, la Academia Paraguaya de la Lengua Española y la Academia Paraguaya de la Historia; Asunción, Paraguay; e-mail: bmelia@hotmail.com

237| Século XXI, Revista de Ciências Sociais, v.3, nº 1, p.237-248, jan./jun. 2013 ISSN: 2236-6725
} 
La educación indígena es sobre todo un sistema de comunicación que ha sido válido durante siglos y que dio consistencia a un modo de ser que sigue siendo exitoso.

Los pueblos indígenas han mantenido su identidad propia frente a otras sociedades gracias a estrategias, de las cuales una es la educación que permite que el modo de ser y la cultura se reproduzca en las generaciones nuevas, pero también encare con relativo éxito nuevas situaciones.

De la educación tupinambá, el sociólogo Florestán Fernandes (1975, p. 38). decía que se caracterizaba por ser tradicional, sagrada y cerrada. Otros tipos de educación han sido caracterizadas de otra manera. Hay varias definiciones de "educación indígena". Una de ellas fue formulada por el prof. Egon Schaden: Educación es un proceso que abarca actitudes, prácticas y precauciones, conscientes o inconscientes, intencionales o no, que confieren a los miembros del grupo características físicas, mentales y morales necesarias para la vida adulta en el contexto social. Educar es, en fin, formar el tipo de hombre o de mujer que, según el ideal válido para la comunidad, corresponde a la verdadera expresión de la naturaleza humana (Schaden, 1976, p. 23).

¿Se puede decir que esa educación indígena tiene en cuenta la alteridad? Hay una caricatura del hombre y la mujer indígena que viene de los tiempos coloniales, y que dice que "visto un indio, vistos todos". Ustedes mejor que yo saben que esta generalización es enteramente gratuita y falsa. Para un observador sincero y objetivo, la imagen que queda es más bien la contraria: que el indígena hace lo que quiere - con una libertad rayana en la anarquía -, porque él es él, es él mismo. La alteridad es la libertad de ser uno mismo.

La alteridad proyectada que cada pueblo indígena proyecta y reclama para sí, viene a confundirse con la constitución de la persona, con su construcción e ideal. Los ideales de persona no quedan fijados en estereotipos ni fotocopias. La educación crea un modo de ser y estar en el mundo que una realidad biológica nunca podría dar.

En el mundo guaraní, por ejemplo, la persona es una "palabra" única e irreductible, cuya historia será una especie de himno de palabras buenas y bellas, una historia de palabras inspiradas, que ni siquie- 
ra puede ser aprendidas ni memorizadas, y por lo tanto no pueden ser propiamente enseñadas; cada uno es su palabra recibida y dicha con propiedad, que se crea al mismo tiempo que se dice, como una energía que se abre en flor. Estas son las metáforas con las que suelen pensarse y decirse los Guaraní. Otros pueblos tendrán otras expresiones similares.

La acción pedagógica tradicional integra sobre todo tres círculos de relacionamiento: la lengua, la economía y el parentesco. Son los círculos de toda cultura integrada. Pero de todos ellos es la lengua tal vez el más amplio y complexivo.

El modo como se vive este sistema de relaciones caracteriza a cada uno de los pueblos indígenas. Y el modo como lo hace pasar a sus miembros, especialmente a los más jóvenes, constituye la acción pedagógica propia de ese pueblo.

Cuando hago memoria de mi educación, cada uno de nosotros recuerda experiencias que nos parecen decisivas en la educación; soy lo que soy gracias a esa educación, no por el color de la piel ni por la rasgos de rasgos de mi rostro; pero sí probablemente por el modo de mirar y de hablar, de comportarme en sociedad, incluso por el modo de caminar o de comer o por el modo de caminar o el modo de mirar. La verdadera y auténtica educación deja marcas en el cuerpo, en cuanto piel que habitamos. También cada uno de los indígenas puede decir que es "de origen".

La pedagogía y educación se rige por el ciclo de vida. Este ciclo de vida, que se desarrolla en cada cuerpo particular, entre los indígenas no se entiende de una manera individual, sino en familia y en sociedad.

No podemos detenernos en este momento en recorrer todo el camino del ciclo de vida de un indígena, en el cual los momentos "críticos", como la recepción de nombre, la "iniciación" y el nacimiento del primer hijo están fuertemente marcados por acciones pedagógicas - y rituales — en las que interviene una buena parte de la comunidad.

Volvamos, pues, a nuestra memoria. ¿Qué educación he tenido como indígena antes de ir a la escuela? ¿Considero que mi educación ha comenzado en la escuela?

En relación con esta cuestión hay otra previa: ¿en qué lengua he sido educado? Y ahí hay que distinguir hay una lengua antes dela 
escuela y otra lengua en la escuela; y hay que reconocer que la enseñanza de esa primera lengua que llamamos materna, ha sido hecha con mayor éxito y profundidad que cualquier otra lengua aprendida después; nuestra madre y su entorno han sido los mejores lingüistas con quien nos hemos encontrado en nuestra vida.

Entonces, ¿cuál es la filosofía que imprime su lógica a esos pueblos? ¿Cuál es su fuerza para que hayan podido perseverar hasta nuestros días? ¿Podemos aprender algo de ellos?

\section{EDUCACIÓN PARA EL INDÍGENA}

En 1978 un grupo de misioneros católicos nos reunimos en Barranco Vermelho, área Rikbaktsa en la margen derecha del Río Juruena, para reflexionar sobre la educación de los indígenas. Muy tímidamente se incorporó al grupo algún líder indígena -en la época no había profesores indígenas en al escuela-.Percibimos desde el comienzo que estábamos dando, bajo una modalidad u otra, una educación para los indígenas. La educación para los indígenas se hacía fuera de la vida indígena, del teko, de la cultura indígena. Más aún se pretendía sustituirla por otra educación, que en fin de cuentas no era educación porque no nacía ni se desarrollaba desde dentro. Se creaban situaciones de sustitución plena del ambiente indígena y no se escatimaban recursos exteriores ni interiores para ello, como eran los internados. Lo que se pretendía era dar una educación que colocara al indio a la altura de un brasilero capacitado técnicamente y aun ser competitivo con él. Esto llegó a conseguirse.

Ahora bien, aun en estos lugares donde se encubría la identidad indígena, disfrazándola de otra cosa, actuaba una matriz de educación indígena tan fuerte y exitosa que conseguía que los indios continuasen siendo indios.

Lo que puede se dice de la escuela misionera no es muy diferente en la escuela laica de la FUNAI.

¿En qué escuela he entrado? ¿La de una misión, la de la FUNAI, la del Municipio? Si soy profesor, ¿en cuál de ellas estoy contratado y sirviendo? 
¿Desconocían estas escuelas enteramente los métodos educativos de las sociedades indígenas? No del todo, pues implícitamente seguían un método de sustitución y de suplantación.

El contraste entre ambas educaciones se puede ejemplificar en esta tabla de contrastes:

\begin{tabular}{|c|c|}
\hline EDUCACIÓN INDÍGENA & EDUCACIÓN PARA EL INDÍGENA \\
\hline \multicolumn{2}{|c|}{ Procesos y medios de transmisión } \\
\hline $\begin{array}{l}\text { - Educación informal y asistemá- } \\
\text { tica }\end{array}$ & - Instrucción formal y sistemática \\
\hline - Transmisión oral & - Alfabetización y uso de libros \\
\hline - Rutina de vida diaria & $\begin{array}{l}\text { - Provocación de situaciones de ense- } \\
\text { ñanza artificiales }\end{array}$ \\
\hline - Inserción en la familia & - Trasladado para la sala de clase \\
\hline - Sin escuela & - Con escuela \\
\hline - Comunidad educativa & - Especialistas de la educación \\
\hline - Valor de la acción & - Valor de la memorización \\
\hline - "Aprender haciendo" & - Aprender memorizando \\
\hline - Valor del ejemplo & - Valor de la cosa aprendida \\
\hline - Sacralización del saber & - Secularización del conocimiento \\
\hline - Persuasión & - Imposición \\
\hline - Formación de la "persona" & - Adiestramiento para "hacer cosas" \\
\hline \multicolumn{2}{|c|}{ Condiciones de transmisión } \\
\hline $\begin{array}{l}\text { - Proceso permanente durante toda } \\
\text { la vida }\end{array}$ & $\begin{array}{l}\text {-Instrucción intensiva durante algunos } \\
\text { años. }\end{array}$ \\
\hline - Armonía con el ciclo de vida & $\begin{array}{l}\text { - Sucesión de materias que tienen que } \\
\text { ser estudiadas dando saltos de una para } \\
\text { otra }\end{array}$ \\
\hline $\begin{array}{l}\text { - Graduación de la educación con- } \\
\text { forme a la maduración psicosocial } \\
\text { del individuo }\end{array}$ & $\begin{array}{l}\text { - Estudio obligatorio de un currículo } \\
\text { determinado de antemano para todos }\end{array}$ \\
\hline \multicolumn{2}{|c|}{ Naturaleza de los conocimientos transmitidos } \\
\hline $\begin{array}{l}\text { - Habilidad para la producción to- } \\
\text { tal de los propios artefactos }\end{array}$ & $\begin{array}{l}\text { - Manipulación de tecnología importa- } \\
\text { da e instrumentos de un trabajo }\end{array}$ \\
\hline $\begin{array}{l}\text { - Integración de los conocimientos } \\
\text { dentro de una totalidad cultural. }\end{array}$ & $\begin{array}{l}\text { - Segmentación de los conocimientos } \\
\text { adquiridos }\end{array}$ \\
\hline $\begin{array}{l}\text { - Integración correcta en la organi- } \\
\text { zación tribal nacional }\end{array}$ & $\begin{array}{l}\text { - Adaptación dentro de un estrato o } \\
\text { clase de la sociedad }\end{array}$ \\
\hline
\end{tabular}


EDUCACIÓN INDÍGENA

Procesos y medios de transmisión

Funciones sociales de la educación

- Integración de las generaciones con respecto a la vida de los viejos

- Preservación y valorización del saber tradicional en vista a una innovación coherente

- Selección y formación de personalidades libres
- Alejamiento y cambio

- Adaptación continua a las novedades, incluso cuando todavía no es comprendida

- Masificación en lo genérico

Los indígenas sienten como una amenaza real, apremiante e ineludible, los intentos que les llevan a la pérdida de la alteridad y la disolución de las diferencias. Esta pérdida y disolución, para algunos, se relaciona incluso de manera directa y casi exclusiva con la escuela. La escuela sería un factor importante de generalización y de uniformidad. Escolarizado el indígena no es ya el otro, sino un individuo más en una sociedad llamada brasileña, o paraguaya, o argentina, o chilena, que por otra parte tampoco se sabe muy bien como caracterizar.

Es un hecho que las escuelas para los indígenas han sido y continúan siendo coloniales. -y creo que tanto en Brasil, como en Bolivia, Chile, en Argentina, en el Perú, en Ecuador y hasta en México-.

Los ataques a la alteridad y a la diferencia se han hecho de forma múltiple, pero tal vez los podemos resumir en estos tópicos: imposición de una lengua general o nacional, currícula también nacionales, y profesores para indígenas.

\section{LOS DESAFÍOS ACTUALES}

Las respuestas que han dado los pueblos indígenas en cunato protagonistas se pueden se pueden considerar conquistas, por lo menos parciales. Las conquistas estuvieron duplicando por contraste lo que parecían haber sido las grandes derrotas: conquistados por los "libros de muerte", los indígenas pidieron y llegan a hacer ahora libros y cartillas en lengua indígena — previa la escritura de cada una de esas lenguas - Una triste herencia de la educación colonial y 
dependiente de sistemas misioneras o nacionales es que el legado de que muchas de esas instituciones, reservaron para sí un instrumento técnico para sí, cual es de la ortografía, que aunque es convencional, arrastra consigo otros aspectos fundamentales de la lengua como son la gramática y las reglas de composición y las más amplias de estilo; los léxicos, que a su vez son visiones de mundo -se puede registrar la lengua sin la lengua, es decir descontextualizada de su realidad social y cultura y aún política y económica.

Nada más estrechamente relacionado que educación y economía; por eso, el gran desafío de las escuela indígena dice respecto al la situación económica de la aldea y la planificación del futuro económico de los pueblos indígenas; será posible que en el futuro todos los que han pasado por la escuela sean empleados del Estado: profesores, enfermeros, o alcancen la universidad y se vuelvan profesionales liberales.

Las escuelas indígenas reclaman currícula adaptados a la realidad indígena, sobre todo en lo que se refiere a saberes tradicionales y folklóricos, pero también reivindican la preparación, incorporación y contratación de profesores indígenas por parte del Estado y de las instituciones.

¿Son estos pasos suficientes para remontar la corriente de la pérdida de alteridad y recuperación de las diferencias? En otros términos, será ello suficiente para mantener a los pueblos indígenas. A pesar de las muchas presiones exteriores, sabemos que el gran enemigo de los pueblos indígenas son los indígenas, comenzando por aquellos que no lo quieren ser ni parecer, y en primer lugar renuncian a su lengua. De ahí se pasa a todos los demás grados de indio genérico. Un indio no has sido enteramente conquistado hasta que no ha perdido su lengua, aunque con su lengua pueda ser colonizado y perder su identidad como en el caso paraguayo; hablamos guaraní, pero no somos guaraní . Estamos en otra dimensión; hemos aceptado la propiedad privada y la economía de mercado.

La lengua con palabras indígenas puede no ser indígena; la adaptación de currícula y de contenidos puede quedar reducida a algunos detalles folklóricos y a lo obvio; y los profesores ser cooptados por el Estado y las instituciones, con efectos más deletéreos, precisamente porque parece que han sido satisfechas las demandas y exigencias de los indígenas. 
Otra manera, sin embargo, de distraer la acción pedagógica para la alteridad, puede ser la atención tan meticulosa a ciertas características propias y dialectales de ese o aquel grupo dentro de una etnia o pueblo que la acción pedagógica queda del todo fragmentada y atomizada en un sinnúmero de casos particulares, cuya resolución es que cada uno haga lo que pueda y lo que quiera.

He entrado en esa especie de casuística, por que bajo el título de ver la realidad se entra en un innumerable registro de casos, muy rico, por cierto, pero donde el árbol impide ver el monte.

\section{¿EN LA COMUNIDAD O DE LA COMUNIDAD?}

Pero aquí quiero llamar la atención sobre una situación que ocurre con relativa frecuencia. Hay profesores indígenas que provienen precisamente de un sector de jóvenes que por diversas circunstancias no han tenido una educación tradicional; a veces han sido educados en un ambiente de perjuicios e incluso de hostilidad contra sus propias pautas tradicionales. Si todavía saben la lengua, ya han olvidado en muchos casos el sentido de palabras y expresiones de la lengua más arcaica, sobre todo en lo que se refiere a la religión a al sistema de parentesco. Por motivos que tienen una profunda explicación cultural y política, la misma comunidad indígena designa como profesores a sus hijos e hijas menos identificados con el modo de ser tradicional, pero que parecen más integrados con el sistema nacional. Para ello las misiones religiosas tienen todavía un peso considerable ya que la capacitación de dichos profesores se ha llevado a cabo en regímenes de casi internado en instituciones no indígenas.

Pero se da también el fenómeno contrario; son los profesores indígenas los que han vivenciado la conciencia crítica y profética de una comunidad y de un pueblo indígenas, de tal manera que la escuela ha sido el lugar donde se han originado movimientos de resistencia y reivindicación de derechos sobre la tierra, contra la discriminación y desprecio. Profesores y alumnos ya saben situarse de forma diferente frente al estado y la sociedad envolvente. 


\section{UNA ALTERIDAD MODERNA}

Lo que creo más importante cuando se trata de ver cuál es la acción pedagógica para la alteridad es tomar conciencia de que esa alteridad es concebida de modo muy diferente en las llamadas sociedades modernas occidentales y en las sociedades indígenas. La alteridad es siempre en fin de cuentas una filosofía de vida, y no puede ser tratada al margen de lo que de un modo u otro llamamos la construcción de la persona. La educación en la sociedad nacional de muchos de nuestros países está todavía muy marcada por el la capacitación individual en vistas a competencia también individual para producir más y mejor y tener más; para ello la acumulación de conocimientos y de destrezas es uno de los objetivos principales. ¿Es esto también lo que tiene que recibir la educación indígena de parte de sus promotores?

La construcción de la alteridad no solo tiene objetivos propios en una y otra sociedad, sino métodos propios. Ya los he señalado a propósito del ciclo de vida. Entre esos métodos es tal vez uno de los principales la participación de la comunidad. Es precisamente la participación de la comunidad la que asegura una alteridad bien entendida. Cuando la educación es un asunto de relación de un profesor al servicio de una familia cuyo interés único es la educación de su hijo o de su hija, es difícil que se forme la alteridad en una comunidad.

Si la alteridad sólo se vive en comunidad — los individuos no son otros, son simplemente ellos mismos en sí mimos_- la acción pedagógica tendrá que estar muy atenta para ver si no es la sociedad y la comunidad indígena la que se está cambiando mediante la práctica escolar.

Los famosos "internados" de otros tiempos suponían en gran parte una renuncia de la misma comunidad frente a su labor educativa; y lo mismo se diga, en cierto modo de los diversos programas de alimentación escolar.

\section{LA SOLUCIÓN INDÍGENA}

La comunidad indígena, a nivel de pueblo o a nivel de aldea, tiene una racionalidad operante (de lo contrario ya habría desapa- 
recido del todo) que hay que saber descubrir para que las nuevas acciones pedagógicas las puedan seguir practicando.

Es precisamente esa racionalidad la que más se le ha retaceado y negado incluso a los pueblos indígenas. Y sin embrago ahí está su aporte más significativo y necesario.

La acción pedagógica para la alteridad no es un descubrimiento que hace la sociedad nacional para ofrecérselo a los pueblos indígenas, sino todo lo contrario: es lo que los pueblos indígenas todavía le pueden ofrecer a la sociedad nacional. No hay un problema de educación indígena; hay sí una solución indígena al problema de la educación.

Por diversos motivos la educación indígena ha tenido momentos de excesiva timidez, de tal manera que apenas apunta a que se reconozcan su autonomía y sus derechos.

El avá háicha ("como persona indígena") es una fuente de inspiración, no una simple condescendencia benévola.

Pero la sociedad "primitiva" puede ser sentida más profundamente como primordial. Todos somos primitivos. Nuestras raíces son primitivas. No solamente fuimos Guaraní, los seguimos siendo y secretamente lo deseamos ser todavía más y por más tiempo. Hay un primitivo que es primero históricamente, pero que también es un primero ontológico. Es la recuperación del ser primordial. El primitivo no es ni un simple pasado ni un "todavía no", sino el futuro y un "ya" que no sale nunca enteramente de nuestro presente. Raíces, fuentes, son metáforas muy adecuadas de este modo de ser indígena para nosotros.

Las sociedades primitivas - y sus sistemas de educaciónnos conducen a la utopía; ésta es su pedagogía. Hay que tomarlas en serio para renovar nuestra propia sociedad y educación. Escuelas de humanidad deberían ser las escuelas indígenas. La pregunta es entonces, no cómo entra la escuela en la educación indígena sino cómo entra la educación indígena en la escuela; y para ello es necesario que la educación indígena no tenga miedo de ser lo que ella es, no tenga miedo de ser feliz y de ser humana.

La alteridad indígena como fruto de la acción pedagógica no solo mantendrá su diferencia, sino que podrá contribuir a que haya un mundo más humano de alteridades libres. 


\section{REFERENCIAS}

FERNANDES, Florestán. Investigação etnológica no Brasil e outros ensaios. Petrópolis: Vozes, 1975.

SCHADEN, Egon. Educação indígena. In: Problemas Brasileiros, São Paulo, XIV, 152, pp. 23-32, 1966,

MELIÀ, Bartomeu. Educación indígena y alfabetización. Asunción: CEPAG, 2008.

Santa Maria, 19 abril de 2012.

Unversidade Federal de Santa María, RS, Brasil. 
